\title{
Numerical modelling of hydrogen release and dispersion
}

\author{
Vlad Mihai Pasculescu ${ }^{1 *}$, Marius Cornel Suvar ${ }^{1}$, Ligia Ioana Tuhut ${ }^{1}$, and Laurentiu \\ Munteanu ${ }^{1}$ \\ ${ }^{1}$ National Institute for Research and Development in Mine Safety and Protection to Explosion - \\ INSEMEX, 32-34 G-ral Vasile Milea street, 332047, Petrosani, Hunedoara county, Romania
}

\begin{abstract}
Hydrogen is the most abundant element on earth, being a low polluting and high efficiency fuel that can be used for various applications, such as power generation, heating or transportation. As a reaction to climate change, authorities are working for determining the most promising applications for hydrogen, one of the best examples of crossborder initiative being the IPCEI (Important Project of Common European Interest) on Hydrogen, under development at EU level. Given the large interest for future uses of hydrogen, special safety measures have to be implemented for avoiding potential accidents. If hydrogen is stored and used under pressure, accidental leaks from pressure vessels may result in fires or explosions. Worldwide, researchers are investigating possible accidents generated by hydrogen leaks. Special attention is granted to the atmospheric dispersion after the release, so that to avoid fires or explosions. The use of consequence modelling software within safety and risk studies has shown its' utility worldwide. In this paper, there are modelled the consequences of the accidental release and atmospheric dispersion of hydrogen from a pressure tank, using state-of-the-art QRA software. The simulation methodology used in this paper uses the "leak" model for carrying out discharge calculations. This model calculates the release rate and state of the gas after its expansion to atmospheric pressure. Accidental release of hydrogen is modelled by taking into account the process and meteorological conditions and the properties of the release point. Simulation results can be used further for land use planning, or may be used for establishing proper protection measures for surrounding facilities. In this work, we analysed two possible accident scenarios which may occur at an imaginary hydrogen refuelling station, accidents caused by the leaks of the pressure vessel, with diameters of 10 and $20 \mathrm{~mm}$, for a pressure tank filled with hydrogen at $35 \mathrm{MPa} / 70 \mathrm{MPa}$. Process Hazard Analysis Software Tool 8.4 has been used for assessing the effects of the scenarios and for evaluating the hazardous extent around the analysed installation. Accident simulation results have shown that the leak size has an important effect on the flammable/explosive ranges. Also, the jet fire's influence distance is strongly influenced by the pressure and actual size of the accidental release.
\end{abstract}

\footnotetext{
*Corresponding author: vlad.pasculescu@insemex.ro
} 


\section{Introduction}

There is currently widespread interest in hydrogen and the role it may play as the fuel of choice for the clean fuel-cell vehicles of the future. Hydrogen is a light gas and has higher diffusion coefficient which means that hydrogen has higher tendency to go upwards and mix quickly with air (because of higher diffusion coefficient) in comparison to other hydrocarbons. However, it has wider explosion limits (4 to 75.6\%), low ignition energy, very high burning velocity and susceptibility to detonation. These properties suggest that hydrogen presents different safety challenges than other hydrocarbon fuels. These unique features of hydrogen have been safely managed on an industrial scale for many years but, in a retail environment for refuelling hydrogen powered vehicles, industrial safety measures would be inappropriate and the proximity of the public unavoidable [1].

Traditional energy is facing a crisis, and the demand for alternative energy is growing. The zero emission potential of hydrogen energy in automotive applications has attracted increasing attention. Fuel cell electric vehicles using hydrogen as fuel are being developed globally. It is estimated that by 2050 , the share of such cars in the light vehicle market will reach $20 \%$.

As an important infrastructure in the application of hydrogen fuel cell vehicles, hydrogen refuelling stations have received extensive attention for their safety. The overall number of hydrogen refuelling stations in the world is still small, and the cumulative operating time is relatively short. In recent years, hydrogen energy accidents have also occurred. Some studies use computational fluid dynamics (CFD) and other software to simulate the diffusion or explosion of hydrogen refuelling stations. Other studies conducted worldwide aim a quantitative risk assessment [1].

Safety issues related to the use of hydrogen have seen an uprising interest all over the world [2]. International Association for Hydrogen Safety "HySafe" is the focal point for all hydrogen safety related issues, founded by an international nonprofit institution by the European Commission co-funded network of excellence [3].

In Europe, in 2017 was launched the European Hydrogen Safety Panel (EHSP) initiative, established by the Fuel Cells and Hydrogen Joint Undertaking 2 - FCH 2 JU. The mission of EHSP is to assist the programme and projects in assuring that hydrogen safety is properly managed and to promote and disseminate hydrogen safety culture outside the programme [4].

Many researchers discussed hydrogen safety issues and presented their research results in recent international scientific conferences [1, 5-7]. Others discussed and tried to provide an overview of the current status of hydrogen safety research worldwide and an overview of experimental databases relevant to hydrogen safety standards [8].

There have been developed specific software for modelling and studying the gas dispersion, software which manage to predict various gases discharge and dispersion with high accuracy, the mathematical models sitting behind being validated by physical experiments. One of the most commonly used software in this respect is PHAST by DNV, able to analyse the sequence of the accident from the release of the chemical material to the explosion or toxic dispersion. A major advantage of the software is that it does not require a difficult input of parameters and does not consume to may resources. However, it generates important and reliable data and information for risk and safety assessment [9].

PHAST is one of the most widely used software for safety engineering applications, many company engineers, competent authorities and other researchers using it for predicting the dispersion of hazardous materials. $[10,11,12,13]$

In this study, the main input parameters involved in the calculation of various model outputs are related to storage, atmospheric, release and orographic conditions. 
For the general public to use hydrogen as a vehicle fuel, they must be able to handle hydrogen with the same degree of confidence as conventional liquid and gaseous fuels. The hazards associated with jet releases from accidental leaks in a vehicle-refuelling environment must be considered if hydrogen is stored and used as a high-pressure gas since a jet release can result in a fire or explosion [13].

This paper uses Phast software to simulate the hydrogen dispersion distance and jet fire radiation in case of a hydrogen refuelling station under certain accident conditions.

The study considers the dynamics of hydrogen as a single component. In Phast, events are modelled based on the process conditions, atmospheric conditions and release point properties. Refuelling station design and operations data s close to the real ones are used as inputs for the modelling. Some of the parameters, such as weather conditions, wind direction and release elevation are inherently difficult to define with exactitude $[14,15]$; as such, typical values were used.

An imaginary hydrogen filling station for cars is used in the determination of 'external safety' or third party distances for the installations and the pipe work for three different sizes of hydrogen filling stations. For several failure scenarios "effect" distances are calculated for car filling at $35 \mathrm{MPa}$ and $70 \mathrm{MPa}$.

\section{Materials and methods}

\subsection{Hydrogen applications in road transport}

Romania's road transport sector is still strongly dependent on fossil fuels and hydrogen is one of the solutions that can be deployed to decarbonise energy use in this sector, especially in heavy-duty road transport, which represents approximately $34 \%$ of the energy use in road transport. Hydrogen can also play a role in the decarbonisation of passenger car transport, especially in the larger car segment and for consumers who need cars with large driving ranges. Furthermore, Romania's railway sector is still dependent on fossil fuels for $57 \%$ of its energy use. Together with further electrification, deployment of decarbonised hydrogen can be one of the solutions to reduce greenhouse gas emissions from the Romanian rail sector.

According to in development hydrogen use related policies, Romania seems to consider hydrogen applications as a long-term perspective. Romania's National Energy and Climate Plan does not include specific objectives or targets for the production or use of hydrogen, nor hydrogen specific policies and measures. In May 2019, Romania hosted the International Conference on Hydrogen Production, "providing a forum to exchange on the latest technological advances, to disseminate new research developments in the areas of hydrogen production and use, and to debate on the future directions and priorities for the deployment of a hydrogen economy for a sustainable future". According to the National Energy and Climate Plan, Romania considers hydrogen deployment mainly in the transport, gas and power sectors [16 - 18].

\subsection{Technical requirements for the design, construction and operation of hydrogen fuel stations for stationary applications}

Hydrogen refuelling stations have to include the following basic technical systems: a hydrogen gas supply system or an on-site hydrogen generation system, a hydrogen gas compression system, a purification system, a storage system and a hydrogen metering system. Each technical system in the configuration of a hydrogen refuelling station consists 
of interconnected components that determine the construction and design specific to the station $[19,20]$.

The main components of the hydrogen supply station, provided with the necessary mechanical, electrical and protective equipment and accessories are:

- a transport system for the supply / storage of low pressure hydrogen gas or an on-site hydrogen generator;

- a compressor for compressing hydrogen gas;

- a metal buffer tank for storing hydrogen gas at high pressure;

- a pre - cooling system that ensures a temperature of $-40^{\circ} \mathrm{C}$ for the distributor;

- a fuel dispenser (pump) for refuelling vehicles.

The compressor must provide the necessary pressure for the hydrogen supply:

- for buses and trucks - $35 \mathrm{MPa}$ (350 Bar);

- for cars - $70 \mathrm{MPa}(700 \mathrm{Bar})$.

The metal storage buffer tank is a high pressure tank of 85 to $100 \mathrm{MPa}$ at a compressor pressure of $70 \mathrm{MPa}$ and 40 to $50 \mathrm{MPa}$ at a compressor pressure of $35 \mathrm{MPa}$. The distributor combines components of the hydrogen filling station for the supply of hydrogen fuel under pressure, through which the vehicle is supplied with hydrogen gas, and includes at least one distribution box, a gas meter, a fuel hose and a nozzle of the fuel tank. The distributor must be protected by an insulating body containing technological piping, a dosing system, a fuel hose and measuring, control and auxiliary equipment. The distributor must meet the requirements of ISO 17268: 2020 "Gaseous hydrogen land vehicle refuelling connection devices". Figure 1 presents a schematic diagram of a hydrogen refuelling station, including its components, configured with an on-site hydrogen generator $[19,20]$ while Figure 2 shows the graphic representation of a typical hydrogen refuelling station [19].

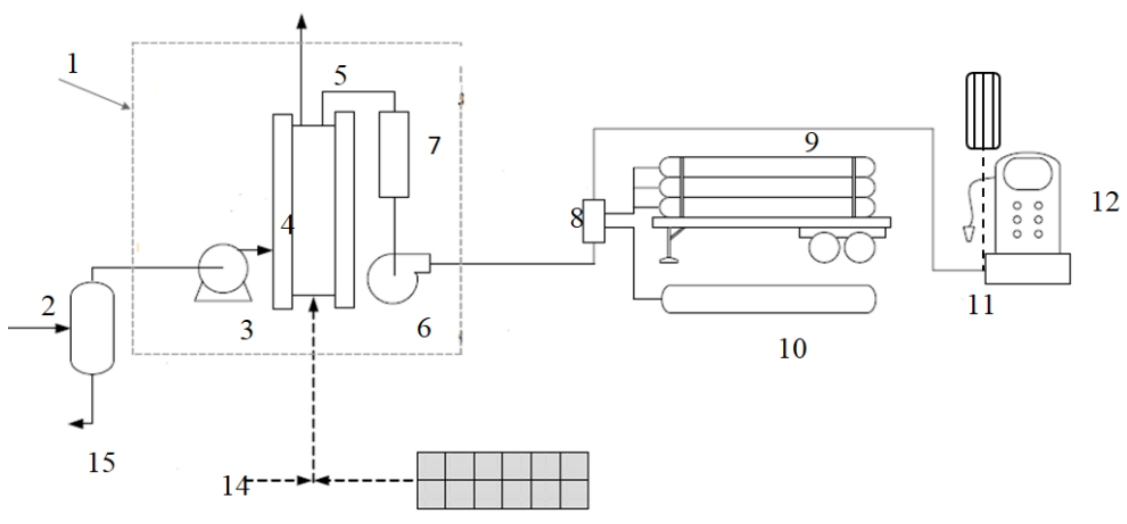

13

Fig. 1. Schematic diagram of a hydrogen refuelling station [20]

where:

1 - an electrolysis installation;

2 - a metal tank for potable water;

3 - a water pump;

4 - an electrolyzer;

5 - residual oxygen flow;

6 - gas compressor with piston;

7 - a hydrogen purifier and dehydrating agent;

8 - a system for controlling the cascade storage of hydrogen;

9 - cascade storage of hydrogen at low pressure in a trailer with tube (or metal hydride);

10 - a fixed metal buffer tank for hydrogen gas compressed at high pressure; 
11 - a pre-cooling system / installation;

12 - compressed hydrogen distributor at high pressure;

13 - a photovoltaic collector field;

14 - electricity supplied from the power network;

15 - purified waste water.

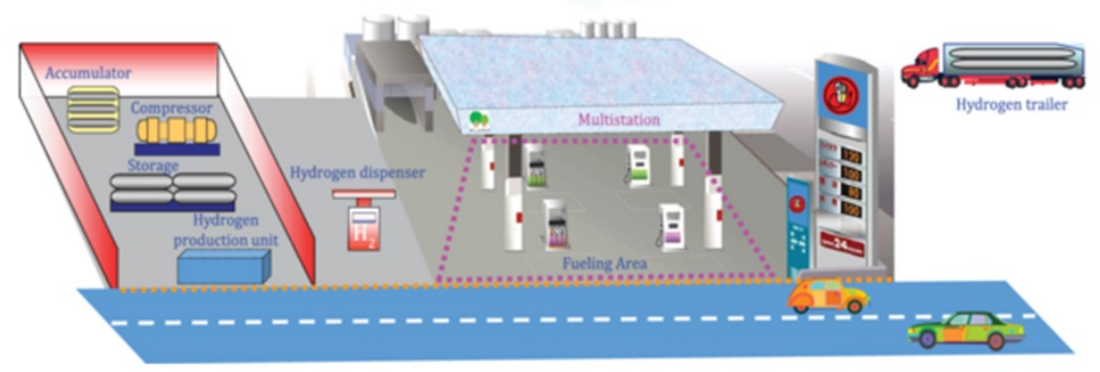

Fig. 2. Example of a hydrogen refuelling station (ISO 19880-1:2020) [8]

\section{Case study}

\subsection{Consequence modelling - accident simulation}

Loss of containment of hazardous toxic/flammable/explosive materials from process vessels/pieces of equipment is a major source of concern in related industries. Such leakages/ruptures often result in fire, explosion, toxicity and/or commercial losses.

Leakages of toxic/flammable/explosive gases present danger, not only within the nearby area but also to communities in the surrounding area especially if the leak is on a large scale $[21,22]$. The need for consequence modelling of process plants and hazardous storage facilities continues to become more prominent as a result of a global drift towards larger and more complex units that handle toxic/flammable/explosive materials, operating under hazardous temperature and pressure conditions.

The magnitude of loss containment, dispersion and consequence are governed by several factors, including material storage condition/properties, characteristics of the leak source and ambient conditions [1, 23, 24].

Meteorology has a strong influence on the outcome of a release, as well as on the spatial distribution of plant physical components

Consequence modelling refers to the calculation of numerical values (or graphical representation) that describes the credible physical outcomes of loss of containment scenarios involving flammable, explosive and toxic materials with respect to their impact on people, assets or safety functions [25]. The consequence modelling in this study focuses on the consequences of a hydrogen release from a vehicle refuelling station. Consequence models are typically nonlinear and multidimensional; hence they are solved using computers embedded in specialised software packages.

\subsection{Risks in Hydrogen Refuelling Stations}

Hydrogen refuelling stations must be as safe as gasoline stations. The facility of hydrogen refuelling stations must be safe. As well, there is known that the storage of hydrogen is an 
important aspect of refuelling station design and construction. In fact, the storage system accomplishes two major roles in hydrogen delivery: increase of storage working capacity and regulation of delivery flow rate [26]. The main safety aspects at the user interface are related to the risk associated with a potential ignition of a hydrogen leakage at the station or at the vehicle. Hydrogen refuelling station may be a complex architecture since it must include additional devices that are essential to deliver the hydrogen to customers, such as compressor unit that is required to compress hydrogen to a required pressure, production facility (in case on-site refuelling station). For these reasons, risk of hydrogen in the service station must be well evaluated and the code and standards for safety must be updated in order to take into account this hydrogen peculiarity. These safety issues and specifics may affect the public perception of installing a hydrogen refuelling station, especially those that live close to the facility.

\subsection{Software tools}

Phast (Process Hazard Analysis Software Tool) is a comprehensive consequence analysis tool. It examines the process of a potential incident from the initial release to far field dispersion, including modelling of pool vaporisation and evaporation, and flammable and toxic effects. Phast is able to simulate various release scenarios such as leaks, line ruptures, long pipeline releases and tank roof collapse in pressurised / unpressurised vessels or pipes. Phast 8.4. has been used in this paper.

Phast is software that has been validated using experimental data by a number of individuals and organizations. Phast is a comprehensive line analysis tool for line analysis of the danger and determination of secure privacy.

An accidental toxic/flammable/explosive gas release may have serious consequences on neighbouring population. Concern for public safety has led to the establishment of safety perimeters, within which land use planning is strictly controlled. It is important that these safety perimeters be established using the best scientific knowledge available, and that the level of uncertainty be minimised. The application of Phast software is quite flexible, allowing the user to customize values for a wide range of model parameters. Users of the software have found that simulation results may depend considerably on the values chosen for some of these parameters [10].

\subsection{Model building and accident simulation}

Most hydrogen refuelling stations work at $35 \mathrm{MPa}$ (350 Bar) - for buses and trucks and 70 $\mathrm{MPa}$ (700 Bar) - for cars. Within the paper, there is studied the hydrogen refuelling and storage equipment that may leak in the $35 \mathrm{MPa}$ and $70 \mathrm{MPA}$ hydrogen refuelling station. According to risk assessments carried out by other authors, the high accident rate is the pipeline leakage and valve damage caused by structural defects, and the emergency situation caused by the failure of opening and closing. Diameters of $10 \mathrm{~mm}$ and $20 \mathrm{~mm}$ are used for simulating the leakages, for a pressure tank filled with hydrogen at 350/700 bar. A typical environment with a wind speed of $1.5 \mathrm{~m} / \mathrm{s}$ and a moderate atmospheric stability of $\mathrm{E}$ is used within the article. When hydrogen leaks, the probability of being ignited immediately is relatively low. If the leak continues, the leaked hydrogen will diffuse into the atmosphere, and the combustible gas detector will detect the hydrogen and then send an alarm, and the emergency shut-off valve will act to block the leak. It takes $18.75 \mathrm{~s}$ from the start of the leak to the stop of the leak. The paper studies the combustible gas cloud dispersion model $18.75 \mathrm{~s}$ after the leak occurs. 


\section{Results and discussion}

\subsection{Dispersion}

Hydrogen has low density, large diffusion coefficient, and wide explosion limit and fast flame speed. Under standard atmospheric pressure, the explosion limit of hydrogen is between $4.0 \%$ and $75.6 \%$. For performing the simulations in Phast software, the following input parameters have been set for the weather conditions: wind speed $-1.5 \mathrm{~m} / \mathrm{s}$, Pasquil stability: E - moderately stable - less overcast and less windy night than $\mathrm{D}$; atmospheric temperature $20 \mathrm{degC}$; Relative humidity $70 \%$; Solar radiation flux $0.5 \mathrm{~kW} / \mathrm{m} 2$. The source term considered is "Leak": a hole in the tank results in the release of Hydrogen to the atmosphere. The discharge calculations are carried out in Phast using "leak" model, which calculates release rate and state of the gas after its expansion to the atmospheric pressure. Relevant input parameters corresponding to the 4 accident scenarios considered are presented in Table 1 below.

Table 1. Accident Scenarios

\begin{tabular}{|c|c|c|c|c|}
\hline & Case 1 & Case 2 & Case 3 & Case 4 \\
\hline Material & \multicolumn{4}{|c|}{ Hydrogen } \\
\hline Mass inventory & \multicolumn{4}{|c|}{$1100 \mathrm{~kg}$} \\
\hline State & \multicolumn{4}{|c|}{ Vapour } \\
\hline Temperature & \multicolumn{4}{|c|}{$-20 \operatorname{deg} \mathrm{C}$} \\
\hline Pressure & $350 \mathrm{bar}$ & 350 bar & $700 \mathrm{bar}$ & $700 \mathrm{bar}$ \\
\hline Scenario & \multicolumn{4}{|c|}{ Leak } \\
\hline Orifice diameter & $10 \mathrm{~mm}$ & $20 \mathrm{~mm}$ & $10 \mathrm{~mm}$ & $20 \mathrm{~mm}$ \\
\hline Phase to be released & \multicolumn{4}{|c|}{ Vapour } \\
\hline Concentration of interest & & $4 \%(4$ & $00 \mathrm{ppm})$ & \\
\hline
\end{tabular}

The dispersion charts are shown in Figure 3, Figure 4, Figure 5 and Figure 6.

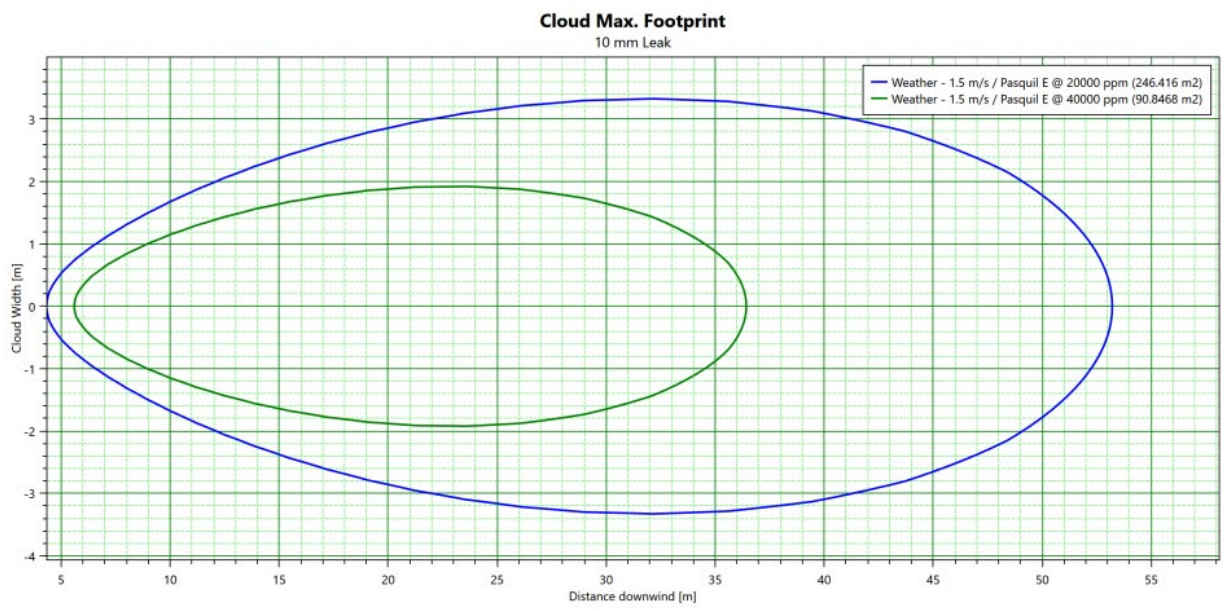

Fig. 3. Case $1-$ Cloud maximum footprint 


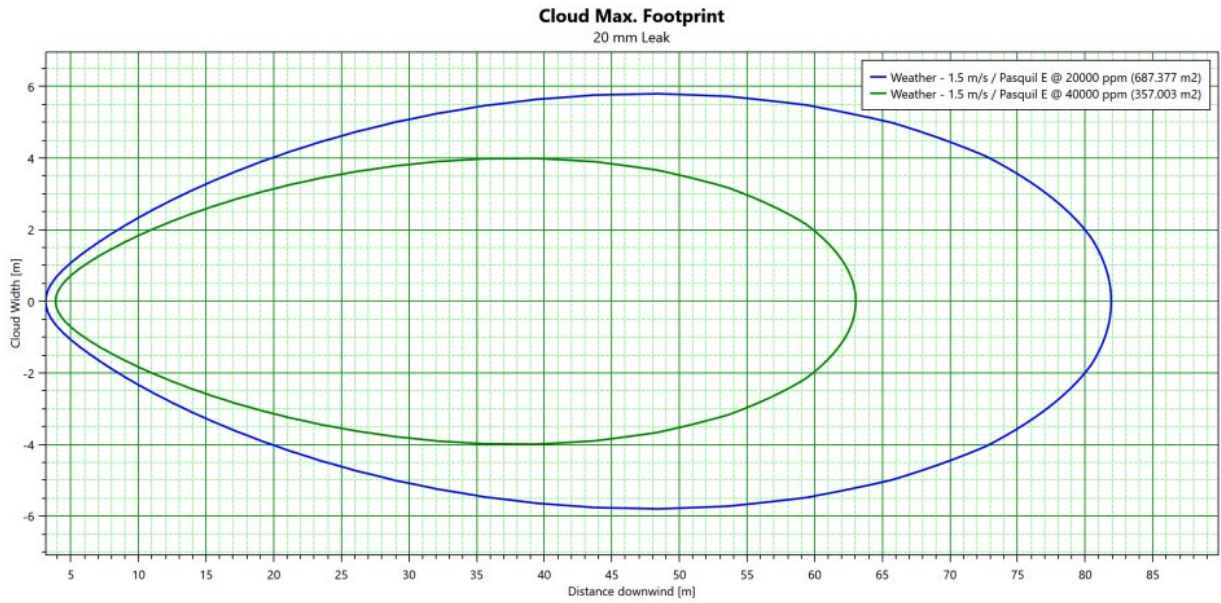

Fig. 4. Case 2 - Cloud maximum footprint

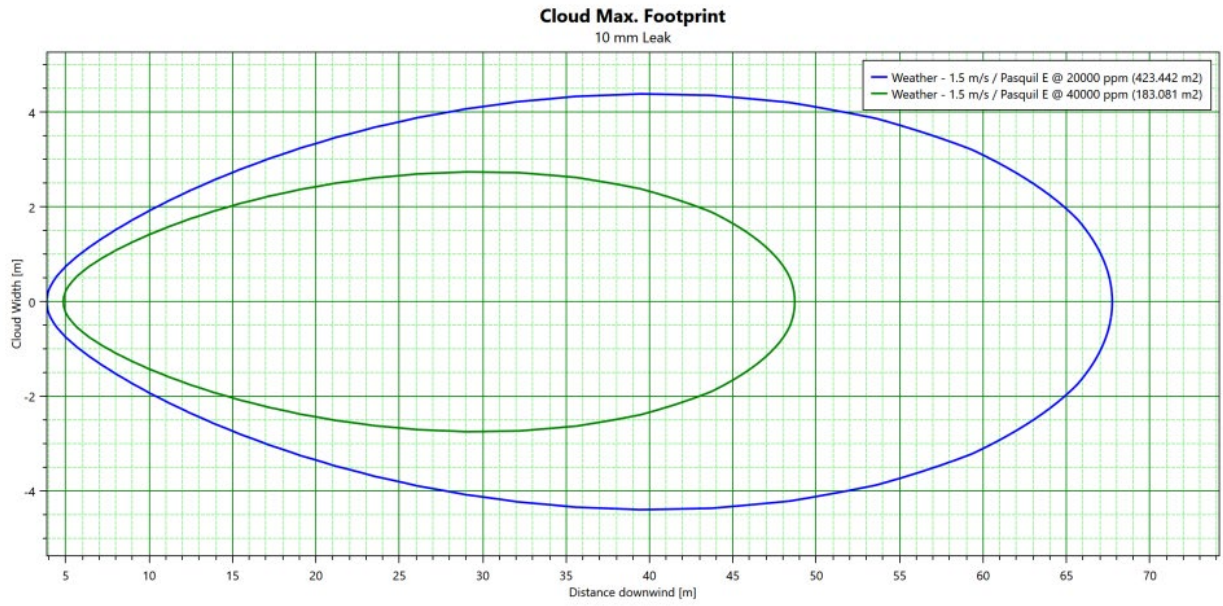

Fig. 5. Case 3 - Cloud maximum footprint

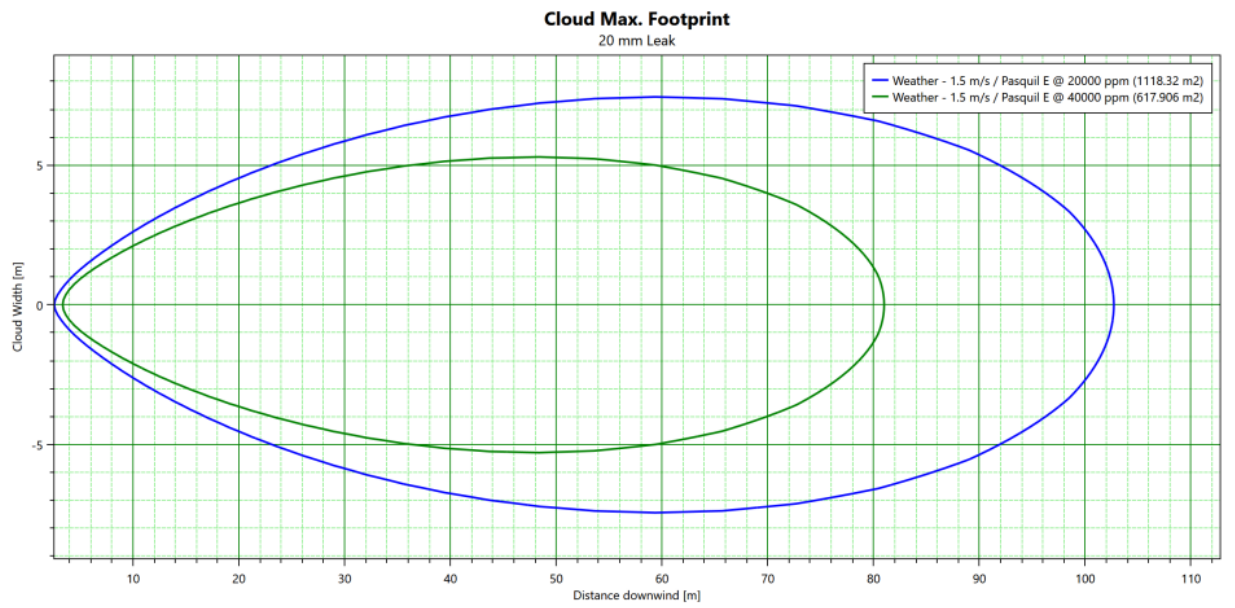

Fig. 6. Case 4 - Cloud maximum footprint 


\subsection{Radiation - Jet fire}

When hydrogen refuelling station leaks, if safety devices such as combustible gas detectors or emergency shut-off valves fail, hydrogen will continue to leak, and a jet fire will occur immediately after ignition. Phast software has been used to simulate the impact of jet fire from hydrogen refuelling station leakage. The simulation results are shown in Figures 7 10 , for the four cases taken into account.

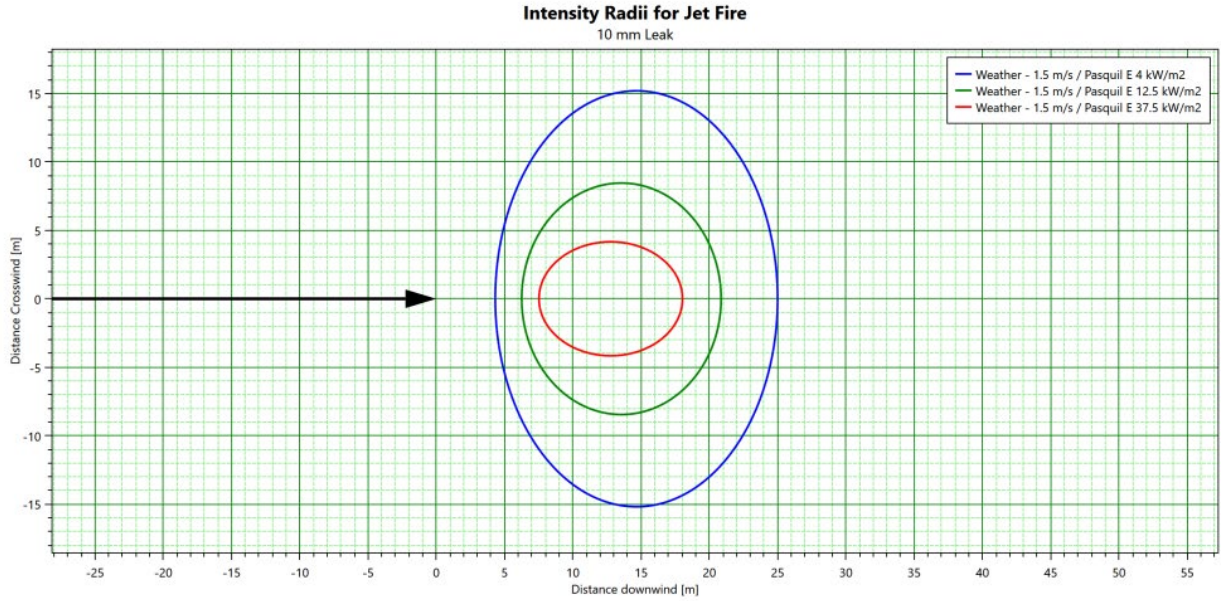

Fig. 7. Case 1 - Intensity radii for jet fire

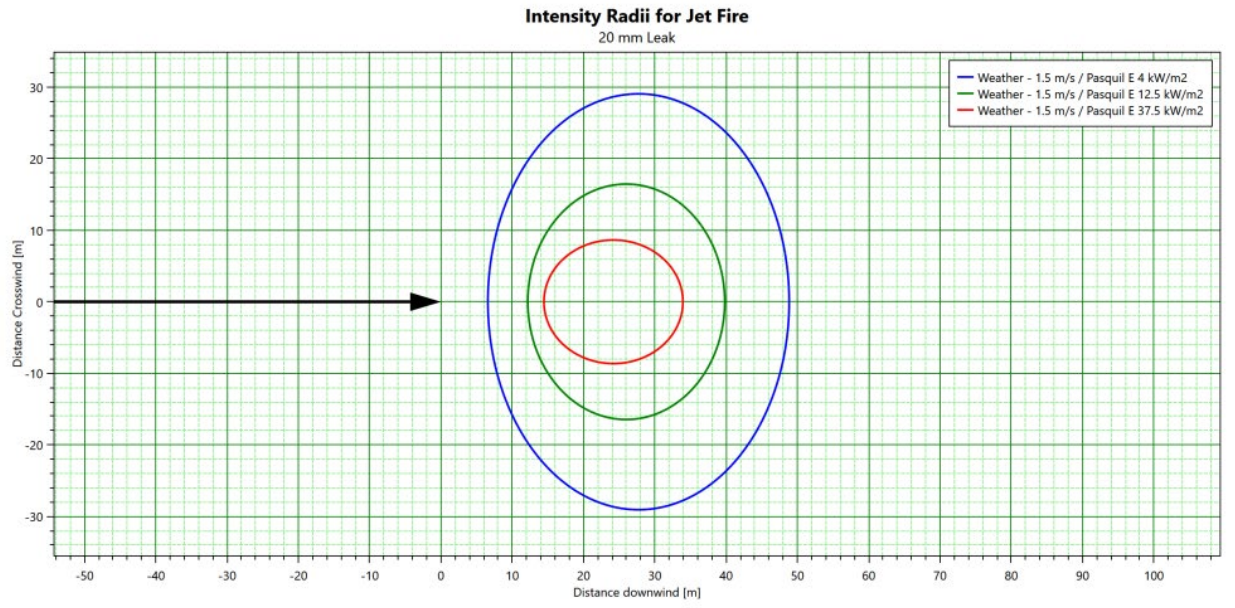

Fig. 8. Case 1 - Intensity radii for jet fire

From Figures 7-10, there cmay be easily read the areas affected by jet fire in the four cases, with regard to the three radiation values of:

- $4 \mathrm{~kW} / \mathrm{m}^{2}$,

- $12.5 \mathrm{~kW} / \mathrm{m}^{2}$

- $37.5 \mathrm{~kW} / \mathrm{m}^{2}$. 


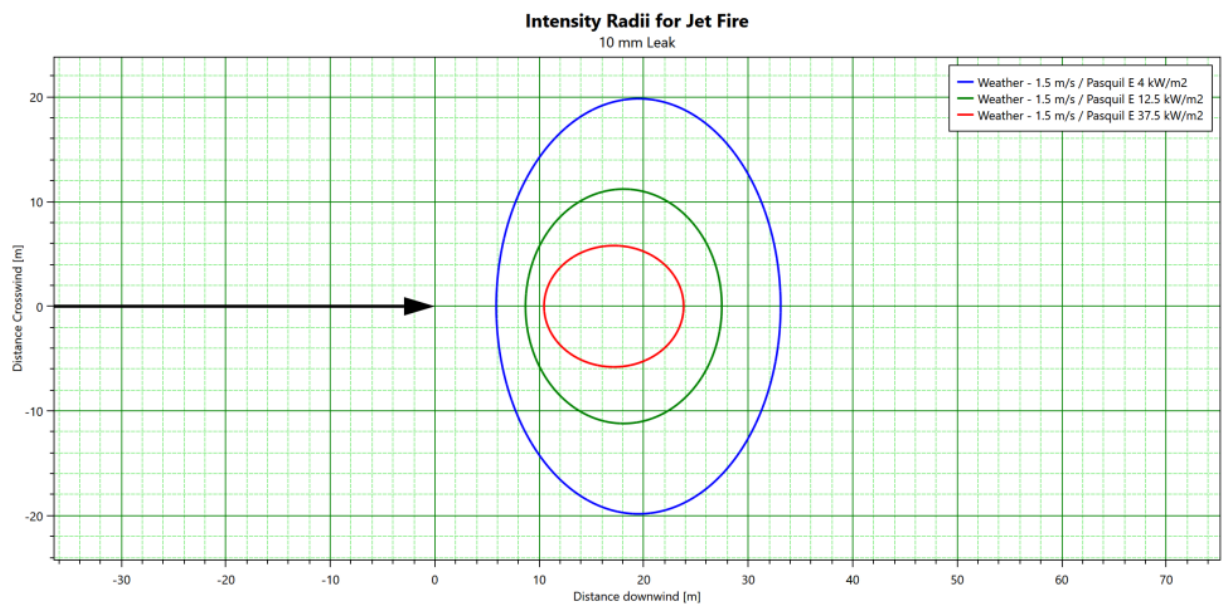

Fig. 9. Case 1 - Intensity radii for jet fire

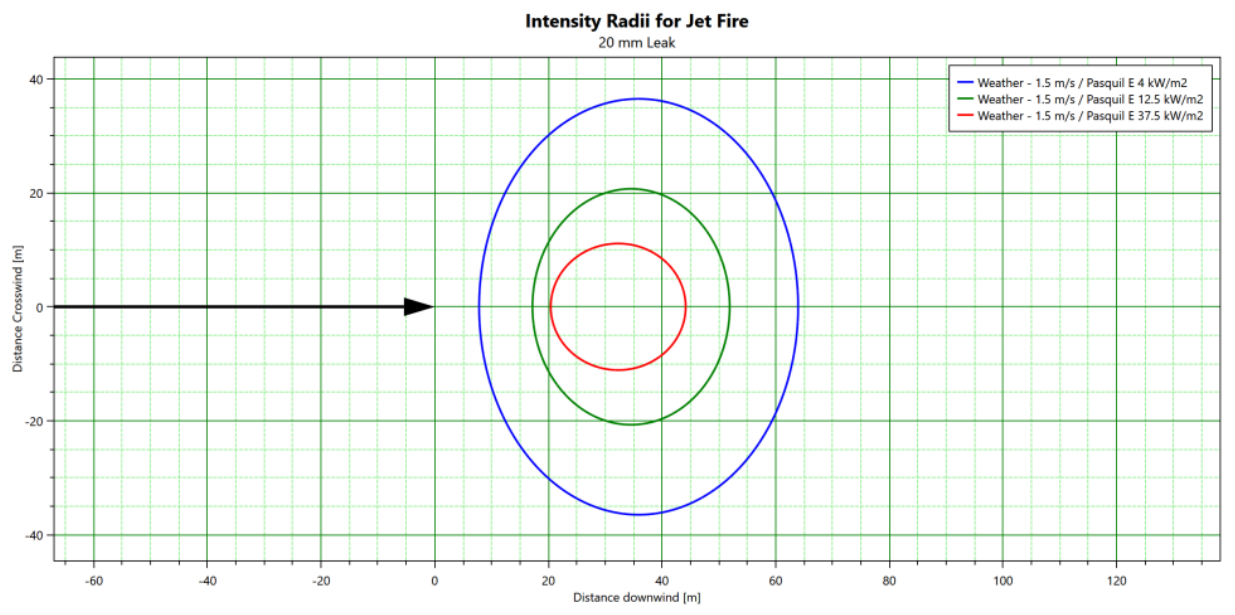

Fig. 10. Case 1 - Intensity radii for jet fire

\section{Conclusions}

This paper uses Phast software to simulate the hydrogen dispersion distance and jet fire radiation in case of a hydrogen refuelling station under certain accident conditions. The study found that after high-pressure hydrogen leaks, the spread of combustible gas cloud is very fast. The flammable and explosive range is positively correlated with the leak size. The leakage volume increases as the leak size increases, and the flammable and explosive range also increases. The influence distance of jet fire radiation is positively correlated with leakage pressure and leak size. The larger the leakage pressure and orifice, the greater the safety distance required. In conclusion, hydrogen refuelling stations can adopt the following various measures to prevent leakage accident risks, such as: the improvement of technical standards and installation requirements in the selection of equipment, pipes and valves. At the equipment and pipelines where leakage may occur, flammable gas detectors are arranged in dense, flame detectors are added, and they are linked with the automatic control room. A reinforced concrete partition wall has to be installed on the end side of the hydrogen gas cylinder, the wall having an appropriate thickness. Also, proper lightning and 
antistatic facilities have to be used in the station, and explosion-proof electrical appliances must be used in the process area.

This paper was developed within the Nucleu-Programme, carried out with the support of Romanian Ministry of Education and Research, project no. PN-19-21-02-01, project title: Techniques and solutions for developing the scientific and technical competences for prevention and protection to explosions (in Romanian: Tehnici si solutii pentru dezvoltarea competentelor stiintifice si tehnice de prevenire si protectie la explozie).

\section{References}

1. Xiatong W., Xiaoxue M., IOP Conf. Ser.: Earth Environ. Sci., 680, 012119, (2021)

2. ISO/TR 15916, (2015)

3. HySafe Project - Safety of Hydrogen as an Energy Carrier, Available on http://www.hysafe.org/

4. European Hydrogen Safety Panel (EHSP), Available on https://www.fch.europa.eu/page/european-hydrogen-safety-panel

5. A. Kovac, M. Paranos, D. Marcius, Proceedings of the 14th Conference on Sustainable Development of Energy, Water and Environment Systems, (2019)

6. K. Wang, X. Zhang, Y Miao, B. He, C. Wang, Proceedings of the 7th International Conference on Energy, Engineering and Environmental Engineering, (2019)

7. F. G. Aarskog, O. R. Hansen, T. Stromgren, O. Ulleberg, Proceedings of the International Hydrogen and Fuel Cell Conference, (2018)

8. W. G. Houf, R. W. Schefer, J. Keller, C. Blake, B. Hoagland, W. Pitts, M. Royle, S. Ruban, S. Jallais, A. Bengaouer, L. Shirvill, T. Gautier, J. Suzuki, D. Willoughby, Proceedings of the 18th World Hydrogen Energy Conference, 443-456, (2010)

9. T. Ruiz-Sánchez, P. F. Nelson, J. L. François, M. J. Cruz-Gómez, A. Mendoza, Int. J. Hydrogen Energy, 37 (8), 6965-6975, (2012)

10. Phast Software features. Available on https://www.dnvgl.com/services/process-hazard-analysissoftware-phast-1675

11. H. W. M. Witlox, M. Harper, A. Oke, J. Stene, J Loss Prev Process Ind, 30, 243-245, (2014)

12. N. Pandya, N. Gabas, E. Marsden, Proceedings of the 14th EFCE International Conference on Loss Prevention and Safety Promotion in the Process Industries (LP), 31, 97-102, (2013)

13. V. M. Pasculescu, E. Ghicioi, M. S. Morar, D. Pasculescu, M. C. Suvar, Quality - Access to Success, 20, 25-30, (2019)

14. M. Leba. A. Ionica, R. Dobra, V. M. Pasculescu, Environ Eng Manag J, 13 (6), 1365-1370, (2014)

15. V. M. Pasculescu, S. M. Radu, E. Ghicioi, D. Pasculescu, T. Niculescu, Proceedings of the 14th International Multidisciplinary Scientific GeoConference SGEM 2014, 1 (2), 43-50, (2014)

16. V. M. Pasculescu, N. I. Vlasin, D. Florea, M.C. Suvar, Quality - Access to Success, 18, 97-102, (2017)

17. V. M. Pasculescu, N. I. Vlasin, M. C. Suvar, C. Lupu, Environ Eng Manag J, 16 (6), 1323-1330, (2017)

18. HyLaw Project documents and policies: Available on https://www.hylaw.eu/info-centre

19. ISO 19880-1, (2020)

20. Notification 2019/0633/BG, (2019), Available on https://bit.ly/3dXkk0W

21. G. B. Babut, R. I. Moraru, Quality - Access to Success, 19 (166), 133-144, (2018)

22. V. M. Pasculescu, N. I. Vlasin, E. Ghicioi, G. D. Florea, M.C. Suvar, Environ Eng Manag J, 18 (4), 889-900, (2019)

23. D. Pasculescu, L. Pana, V. M. Pasculescu, F. Deliu, Mining of Mineral Deposits, 13 (2), 1-16, (2019)

24. F. G. Popescu, D. Pasculescu, M. D. Marcu, V. M. Pasculescu, Mining of Mineral Deposits, 14 (4), 40-46, (2020)

25. M. Suvar, D. Cioclea, I. Gherghe, V. Pasculescu, Environ Eng Manag J, 11 (7), 1235-1239, (2012)

26. M. Casamirra, F. Castiglia, M. Giardina, C. Lombardo, Int J Hydrogen Energ, 34 (14), 54865854, (2009) 